\title{
Poor compliance and increased mortality, depression and healthcare costs in patients with congenital adrenal hyperplasia
}

\author{
Sara Jenkins-Jones', Lotta Parviainen², John Porter², Mike Withe², Martin J Whitaker², Sarah E Holden',
} Christopher LI Morgan', Craig J Currie ${ }^{1,3}$ and Richard J M Ross ${ }^{2,4}$

'Pharmatelligence, Cardiff, UK, 2Diurnal Limited, Cardiff, UK, ${ }^{3}$ Institute of Population Medicine, Cardiff University, Cardiff, UK, and ${ }^{4}$ Department of Oncology and Metabolism, University of Sheffield, Sheffield, UK

Correspondence should be addressed to $R$ Ross

Email

r.j.ross@sheffield.ac.uk

\begin{abstract}
Objectives: To evaluate the risks of depression and all-cause mortality, healthcare utilisation costs and treatment adherence in congenital adrenal hyperplasia (CAH) in the United Kingdom.

Design and methods: A retrospective, matched-cohort study using UK primary-care data from the Clinical Practice Research Datalink linked to hospital and death certification data. Patients diagnosed with CAH and having $\geq 1$ corticosteroid prescription were matched 1:10 to reference subjects. Risk of death and lifetime prevalence of depression were compared using Cox regression models. Direct financial costs were estimated for healthcare contacts. Treatment adherence was measured by medical possession ratio (MPR).

Results: 605 patients with CAH were identified; 562 were matched. 270 CAH patients ( 2700 controls) were linkable to death-certificate data, with adjusted hazard ratio for all-cause mortality 5.17 (95\% Cl 2.81-9.50). Mean (s.D.) age at death in CAH patients was 54.8 (23.9) vs 72.8 (18.0) years in control patients. The prevalence ratio of depression in CAH vs control patients was $1.28(95 \% \mathrm{Cl} 1.13-1.45)$. Mean (s.D.) annual healthcare costs were higher in CAH than controls: at age 0-6 years, $f 7038$ ( $f 14846)$ vs $f 2879$ ( $f 13972, P<0.001) ; 7-17$ years, $f 3766$ ( $f 7494)$ vs $f 1232$ ( $f 2451$, $P<0.001$ ); $18-40$ years, $f 1539$ ( $f 872$ ) vs $f 1344$ ( $f 1620, P=0.007$ ) and $\geq 41$ years, $f 4204$ ( $f 4863$ ) vs $f 1651$ ( $f 2303$, $P<0.001)$. Treatment adherence was lowest in adults, with $141(36 \%)$ of 396 eligible patients having an MPR $<80 \%$. Conclusions: This first analysis of CAH in routine UK healthcare suggests that patients with CAH have increased mortality, depression and healthcare utilisation and low treatment adherence.
\end{abstract}

\section{Introduction}

Congenital adrenal hyperplasia (CAH) comprises a group of genetic disorders in which cortisol synthesis is disrupted (1), leading to deficiencies of cortisol and, potentially, aldosterone with consequent increased production of androgens. Clinical manifestations of classical CAH include acute, life-threatening adrenal crises and androgen excess, resulting in genital ambiguity and hirsutism in females, precocious puberty, infertility and compromised quality of life in both men and women

www.eje-online.org https://doi.org/10.1530/EJE-17-0895
(C) 2018 European Society of Endocrinology Printed in Great Britain
(2, 3). A milder, non-classical (not salt-wasting) form of the disease can produce symptoms such as irregular menstrual periods and fertility problems later in life, but many patients with non-classical $\mathrm{CAH}$ are asymptomatic and most are not treated with corticosteroids; the focus of this paper is, therefore, classical CAH.

The British Paediatric Surveillance Unit has reported that $\mathrm{CAH}$ affects approximately 1:18 000 live-born infants in Great Britain (4). Treatment of CAH since the 1950s 
has taken the form of lifelong replacement therapy with glucocorticoids and, where needed, mineralocorticoids, although no licensed paediatric dose formulation exists for neonates and infants, and there are concerns that the physiological circadian rhythm of cortisol is not successfully mimicked by existing products $(5,6)$. Data from long-term registries have suggested that $\mathrm{CAH}$ is associated with excess mortality and morbidity risk (3), and this may relate to glucocorticoid replacement $(2,7)$.

In this retrospective matched-cohort study, we evaluated the burden of $\mathrm{CAH}$ in a UK population by analysing the risk of depression and all-cause mortality, and estimating healthcare use, costs and adherence to oral corticosteroid therapy.

\section{Patients and methods}

Data were from: the Clinical Practice Research Datalink (CPRD) primary-care data set and linked additional data sets (where eligible): death-certificate data from the Office for National Statistics (ONS) and inpatient and outpatient data from the Hospital Episode Statistics (HES) for England $(8,9,10)$. Approval for this study was granted by the CPRD Independent Scientific Advisory Committee (reference number 15_203).

CPRD is an ongoing database of pseudonymised data collected in a non-interventional way from participating primary-care practices throughout the United Kingdom. At January 2015, it contained more than 13 million research quality patients registered at 684 practices. For more than 7 million patients (54\%) registered with participating English practices, their records can be linked with other data sources, notably HES (containing details of every hospital admission and outpatient appointment in England) and ONS mortality data (the legal repository for the notification of deaths in England and Wales).

The study population were patients with a CAH diagnosis recorded by Read Code (CPRD) or ICD-10 code (HES), as listed in Supplementary Table 1 (see section on supplementary data given at the end of this article), and drawn from patients flagged by CPRD as having acceptable research quality. To substantiate patients' CAH status, we required patients to have at least one prescription for a corticosteroid. Where a patient's records included a conflicting diagnosis, the record was assessed by an endocrinologist (author $\mathrm{R} \mathrm{J} \mathrm{M} \mathrm{R)} \mathrm{to} \mathrm{confirm} \mathrm{the} \mathrm{CAH}$ diagnosis. The date of the patient's first CAH record was the earlier of their first CAH diagnostic record or their first corticosteroid prescription. The patient's index date, equating to start of follow-up, was the latest of the patient's first $\mathrm{CAH}$ record, their registration date or their general practice's up-to-standard date (a CPRD research quality indicator). End of follow-up was the earliest of the patient's death date, transfer from the practice or the practice's last data-collection date. The entire CAH study population participated in the comparative analysis of depression (if matched) and analysis of therapy adherence. In the comparative analyses of all-cause mortality and healthcare use, we considered patients eligible to participate in the appropriate linkage scheme and having index dates within the coverage periods of the linked datasets. In analyses by age group, patients were included if they became eligible for inclusion in that age group at any time in their follow-up period; patients were then observed while their age group interval was concurrent with the data follow-up period. For comparative analyses, patients with $\mathrm{CAH}$ were matched with reference (control) patients randomly selected from CPRD patients having no record of CAH, adrenal crisis or other adrenal insufficiency at any time in their primary-care and linked HES records. CAH patients were matched 1:10 with control patients on year of birth, gender, general practice, registration at case index date and eligibility for linkage to the HES and death-certificate data sets. The last of these criteria, linkage eligibility, was necessary in order to create comparable matched cohorts for analyses based on the linked data sets. Control patients inherited the index date of their matched $\mathrm{CAH}$ patient.

\section{Study endpoints}

\section{Death and depression}

Death was determined from death certification and depression by Read Code in CPRD, by ICD-10 code in HES inpatient data, or by the prescription of antidepressants. A sensitivity analysis considered only those depression outcomes identified by both diagnostic (Read or ICD-10) code and at least one antidepressant prescription.

Lifetime prevalence of depression rather than incident occurrence was compared because the clustering of apparently incident diagnoses around registration date might have led to ascertainment bias in the CAH study arm. Depression was identified not only from ongoing records but also from patients' clinical histories dating from before the start of data follow-up (from records transferred or transcribed from other general practices or from records entered before the practice's up-to-standard date or in the course of the patient's previous period of registration at the practice). 


\section{Treatment adherence}

Medical possession ratio (MPR) was used as a proxy for CAH patients' adherence to oral corticosteroid medications as prescribed. This standard measure was calculated as the total days' supply prescribed over an observation period divided by the duration of that observation period (11). An MPR $<80 \%$ is considered to indicate poor compliance (12).

\section{Healthcare resource use and costs}

Primary-care contacts were identified from CPRD's consultation table, and inpatient admissions and outpatient attendances from the linked HES inpatient and outpatient data sets, respectively. Resource use and costs were analysed in two different subsets of the data: primarycare costs in all CAH and control patients regardless of linkage eligibility, followed from start (index date) to end of CPRD data follow-up; and combined primary- and secondary-care costs in linkage-eligible CAH patients and their controls, followed from the later of their index date and the start of HES follow-up to the end of combined CPRD and HES follow-up. Given that a proportion of identified patients could not be observed in the period in which $\mathrm{CAH}$ first presented, sensitivity analyses were carried out, selecting only those CAH patients (and their controls) who had data follow-up that included their first record of CAH or closely followed it (within 365 days of first CAH and of patient's year of birth).

Each primary-care consultation was classified by consultation type (e.g. clinic, surgery, home visit) and staff role (e.g. doctor, practice nurse) and then assigned an average cost as listed in the Unit Costs of Health and Social Care 2013/2014 from the Personal Social Services Research Unit (PSSRU) (13). Where only the average cost per hour was published, the GP Workload Survey (14) was consulted in order to determine the average length of the consultation, from which the average cost for that consultation could be calculated. Each inpatient admission was allocated a Healthcare Resource Group (HRG) using local payment grouper software (15), thereby aggregating spells of patient care into categories that are homogenous in terms of resource use. The allocated HRG was then linked to the 2013/2014 National Tariff (16) and the relevant cost applied depending upon the nature of the spell. Additional costs relating to excess length of stay, as defined by the National Tariff, were also allocated. Where no cost could be allocated, mean costs were assigned by spell type: elective, emergency or day. Where possible, the main specialty recorded for each outpatient appointment was used to assign a cost from the 2013/2014 National Tariff (16). If a cost could not be applied by main specialty, treatment specialty was used instead. Different costs were applied to first and follow-up appointments. Where a specialty was not listed in the tariff, costs were applied from the 2013/14 NHS Reference Costs (17). The same costs were applied to appointments that were not attended.

\section{Statistical methods}

Baseline characteristics of CAH patients and their controls at index date (start of data follow-up) were aggregated and compared using the independent $t$-test or Mann-Whitney $U$ test depending upon their distribution. Categorical variables were compared using the chi-square test. For the survival analysis, Kaplan-Meier curves stratified by the study arm were produced. Time from index date to death was evaluated using Cox proportional hazards modelling, with adjustments for age, sex, Charlson comorbidity index (18) and index year (omitting sex where results were presented by gender). The proportional hazards assumption was tested by examining the Pearson correlation between Schoenfeld residuals and the rank of survival time for cases that had progressed to death. Lifetime prevalence of depression was compared between study arms by chi-square test. Rates and costs of healthservice use per person year were calculated and compared between $\mathrm{CAH}$ patients and their matched controls using the Mann-Whitney $U$ test. MPR in patients with CAH were presented as summary statistics in tabular form. The point prevalence of corticosteroid-treated CAH patients in the CPRD population was calculated for 30 June 2013 as the number of CAH patients with an index date $\leq 30$ June 2013 and an end of follow-up $\geq 30$ June 2013, divided by the CPRD population with a registered status on that date and presented with 95\% Wilson score confidence intervals.

\section{Results}

We identified 1188 research quality patients having at least one diagnostic code for CAH in the CPRD or linked HES inpatient data. Of these, 67 were excluded because their first $\mathrm{CAH}$ diagnostic record was dated after the end of CPRD follow-up; a further 41 were excluded because they shared a linked identity in HES with another patient; and three with conflicting adrenal diagnoses were excluded as 
probably not having $\mathrm{CAH}$ after scrutiny of their CPRD and HES histories, leaving 1077 patients. Of these, 605 (56\%) had a record of at least one corticosteroid prescription and formed the CAH study population. $354 \mathrm{CAH}$ patients (59\%) were identified through CPRD data alone, 52 (9\%) through HES alone and 199 (33\%) through their records in both CPRD and HES. 367 CAH patients (61\%) were eligible for linkage to the HES and ONS data sets. For the comparative analyses, 562 (93\%) CAH patients could each be matched with 10 non-exposed, control patients. Patient subsets are presented in Supplementary Fig. 1.

\section{Prevalence}

268 CAH patients were prevalent at 30 June 2013, representing a point prevalence of 5.84 per 100000 registered patients (95\% Wilson score CI 5.18-6.58 per 100000 ) or one in 17135 patients (95\% CI one in 19312 15202 patients).

\section{Baseline characteristics}

Table 1 summarises the baseline characteristics of children ( $<18$ years) and adults (18 years and over) at index date (start of data follow-up). Female children with $\mathrm{CAH}$ had a mean age of 5.8 years (s.D. 5.2; median 5, IQR 1-9 years) at the start of follow-up; male children had a mean age of 4.5 years (s.D. 4.8; median 3, IQR 0-7 years). The mean time from first record of CAH (first diagnostic record or corticosteroid prescription) to index date was 2.5 years in girls (s.D. 4.4; median 0, IQR $0-3.1$ years) and 1.6 years (s.D. 3.2; median 0 , IQR $0-10$ years) in boys. For adult women with $\mathrm{CAH}$, the mean age at the start of follow-up was 34.3 years (s.D. 13.7; median 31, IQR 24-39 years) and men 37.5 years (s.D. 17.4; median 31 , IQR $25-47$ years). The mean time from first CAH to index date was 12.6 years in women (s.D. 13.5; median 5.8, IQR 0-24.2 years) and 17.2 years in men (s.D. 15.0; median 19.5, IQR 0-28.1 years). Adult CAH patients had a higher mean body mass index (BMI) than controls: 28.2 (s.D. 6.5$) \mathrm{kg} / \mathrm{m}^{2}$ vs 26.1 (6.1) $\mathrm{kg} / \mathrm{m}^{2}$ (median 26.7 (IQR $23.3-31.2) \mathrm{kg} / \mathrm{m}^{2}$ vs $\left.24.8(22.1-29.0) \mathrm{kg} / \mathrm{m}^{2} ; P<0.001\right)$, respectively. The smoking profiles of $\mathrm{CAH}$ and control patients were similar, but a higher proportion of $\mathrm{CAH}$ patients described themselves as 'ex-drinkers' compared with control patients: $4 \%$ vs $1 \%$ overall $(P=0.001), 3 \%$ vs $1 \%$ in female patients $(P=0.010)$ and $6 \%$ vs $1 \%$ in male patients $(P=0.037)$, respectively. Thirty-nine $(7 \%) \mathrm{CAH}$ patients had records of adrenal crisis, 17 (44\%) were male, 22 (56\%) female. Nine CAH patients had $\geq 1$ adrenal crisis while aged 6 years or younger, 11 aged 7-17 years, 10 aged 18-25 years and 12 aged 26 years or older. There were no records of adrenal crisis in the control patients.

\section{All-cause mortality}

270 CAH patients, matched with 2700 control patients, were eligible for inclusion in the comparison of mortality risk. Mean (s.D.) age at start of mortality follow-up was 23.3 (19.7) years in each cohort, with a mean (s.D.) follow-up of 5.3 (4.3) years in CAH patients and 5.8 (4.5) years in control patients. There were 17 deaths amongst the 270 eligible $\mathrm{CAH}$ patients, corresponding to a crude mortality rate of 11.9 deaths per 1000 person-years (Table 2). Amongst the 2700 eligible control patients, there were 41 deaths, corresponding to 2.6 deaths per 1000 person-years. Kaplan-Meier curves for female, male and all patients and stratified by study arm are shown in Fig. 1. The adjusted hazard ratio (aHR) for all-cause mortality in eligible CAH patients vs their matched controls was 5.95 (95\% CI 3.35-10.56), adjusting for age and sex. When the model was further adjusted to include index (start of follow-up) year and baseline Charlson comorbidity index, the aHR was 5.17 (2.81-9.50). In female patients, the aHR was 6.00 (95\% CI 2.80-12.86), adjusting for age, decreasing to 4.69 (2.05-10.71) when index year and Charlson index were added to the model. In male patients, the aHR was 5.87 (2.41-14.26), adjusting for age, increasing to $6.81(2.68-17.29)$ on the inclusion of index year and Charlson index. Mean age at death in eligible CAH patients was 54.8 years (s.D. 23.9; median 62.0, IQR 34.0-75.0 years), compared with 72.8 years (s.D. 18.0; median 78.0, IQR 71.0-83.0 years) in control patients. In female CAH patients, mean age at death was 55.8 years (s.D. 20.9; median 60.5, IQR 40.0-73.0 years), compared with a mean age of 69.2 years (s.D. 22.3; median 76.0, IQR 70.25-83.25 years) in female control patients. In male CAH patients, mean age at death was 53.3 years (s.D. 27.5; median 72.0, IQR 26.0-77.0 years), compared with a mean age of 76.3 years (s.D. 11.5; median 80.0, IQR 74.0-83.0 years) in male control patients.

\section{Depression}

The lifetime prevalence of depression was $33.5 \%$ in CAH patients vs $26.1 \%$ in control patients, a prevalence ratio of 1.28 (95\% CI $1.13-1.45$, Table 3 ). In a sensitivity analysis in which depression was identified by the presence of both a diagnostic code and an antidepressant prescription, the lifetime prevalence decreased in both 


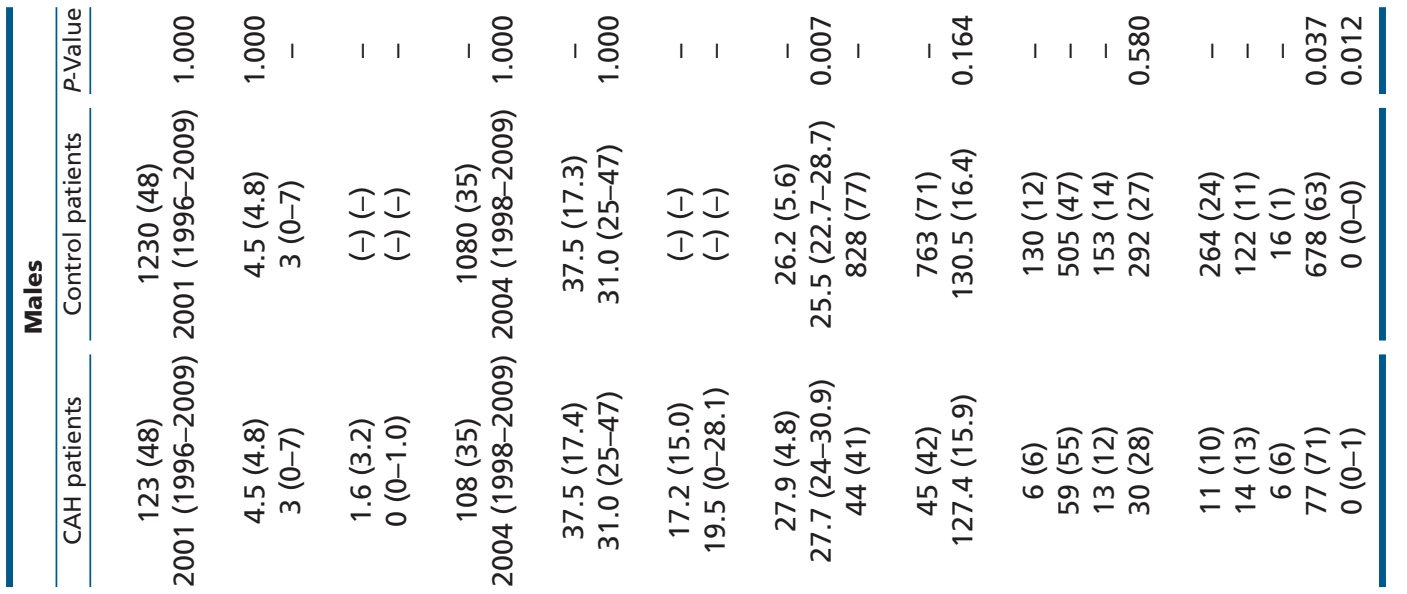

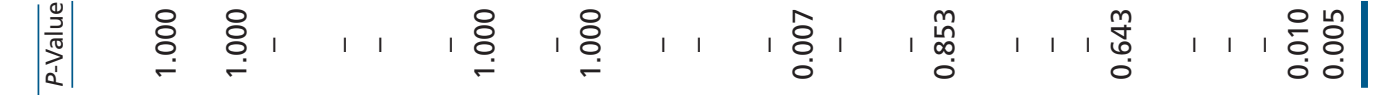

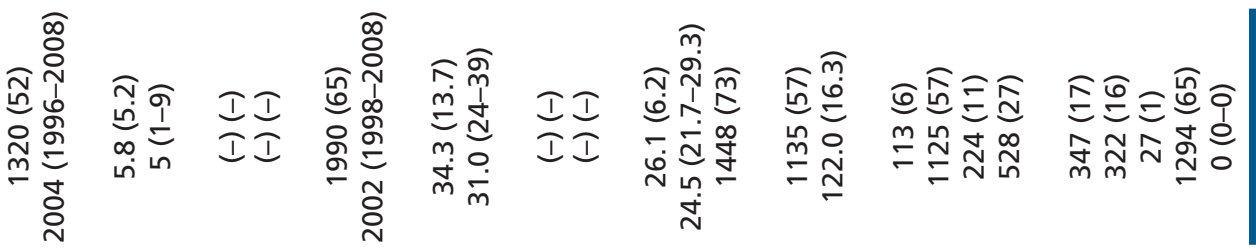

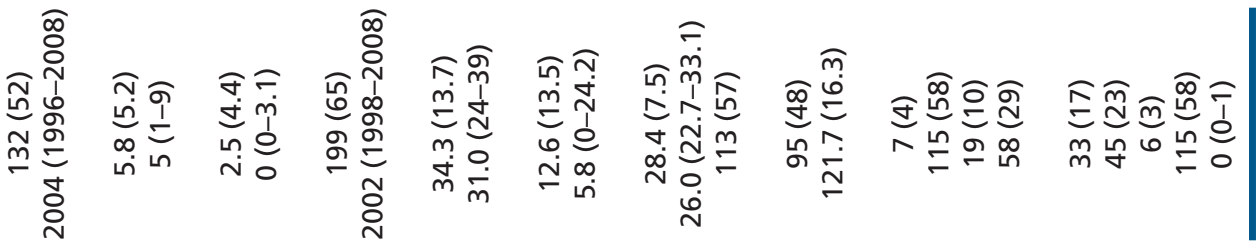

$\stackrel{\circ}{\circ} \stackrel{\circ}{\circ}$

, $\stackrel{8}{\circ}, \stackrel{8}{-}$

$\stackrel{8}{\circ}, 1$,

, $\bar{o}_{0}, 1$

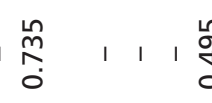

管

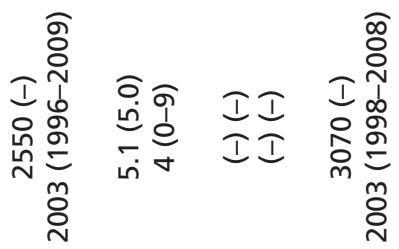

忿离

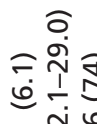

ত్ర

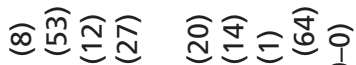

官官

i.

i

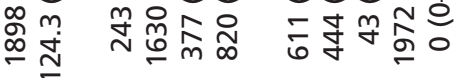

बิे

İ

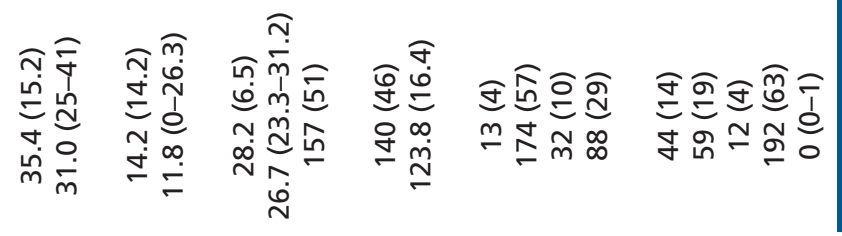

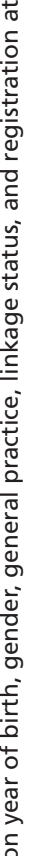

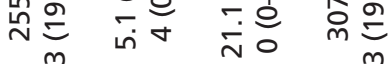


Table 2 Deaths, follow-up time and crude event rates in eligible $\mathrm{CAH}$ patients and matched reference patients.

\begin{tabular}{|c|c|c|}
\hline & CAH patients & Control patients \\
\hline All patients & 270 & 2700 \\
\hline Number of deaths & 17 & 41 \\
\hline Person-years & 1427 & 15535 \\
\hline $\begin{array}{l}\text { Event rate (per } 1000 \\
\text { person-years) }\end{array}$ & 11.9 & 2.6 \\
\hline Males & 117 & 1170 \\
\hline Number of deaths & 7 & 21 \\
\hline Person-years & 575 & 6592 \\
\hline $\begin{array}{l}\text { Event rate (per } 1000 \\
\text { person-years) }\end{array}$ & 12.2 & 3.2 \\
\hline Females & 153 & 1530 \\
\hline Number of deaths & 10 & 20 \\
\hline Person-years & 851 & 8943 \\
\hline $\begin{array}{l}\text { Event rate (per } 1000 \\
\text { person-years) }\end{array}$ & 11.8 & 2.2 \\
\hline
\end{tabular}

study arms: $18.3 \%$ vs $13.2 \%$ in CAH patients and control patients, respectively, but the prevalence ratio compared with controls remained significantly high: 1.39 (1.151.68, Supplementary Table 2). When analysed by age group (children: $\leq 17$ years, younger adults: 18-40 years, and older adults: $\geq 41$ years), lifetime prevalence of depression remained higher in $\mathrm{CAH}$ patients than in control patients, significantly so in children and in the older adults, with prevalence ratios 1.47 (95\% CI 1.032.09 ) and 1.50 (1.30-1.74), respectively (Table 3). Lifetime prevalence was higher in female patients than in males in both cohorts and across all age groups, but the prevalence ratio compared with controls was higher for male patients than for female patients in children and older adults: 2.18 (1.20-3.96) in male children and 1.22 (0.78-1.89) in female children; 1.69 (1.32-2.17) in older adult males and 1.40 (1.17-1.67) in older adult females. The prevalence of depression in male young adult $\mathrm{CAH}$ patients was similar to controls. In the sensitivity analysis, results by gender and age group were similar, with lifetime prevalence reduced but prevalence ratios increased, although reduced patient numbers meant that results were statistically significant only in older adults (Supplementary Table 2).

\section{Healthcare costs}

Total costs are presented by age group in Table 4, with stratified primary and secondary healthcare costs presented in Supplementary Tables 3A, B, C and D and healthcare resource use in Supplementary Tables 4A, B, $\mathrm{C}$ and D. Mean (s.D.) annual total healthcare costs were higher for patients with $\mathrm{CAH}$ than for controls across all age groups: $£ 7038$ ( $£ 14$ 846) vs $£ 2879$ ( $£ 13$ 972) in those
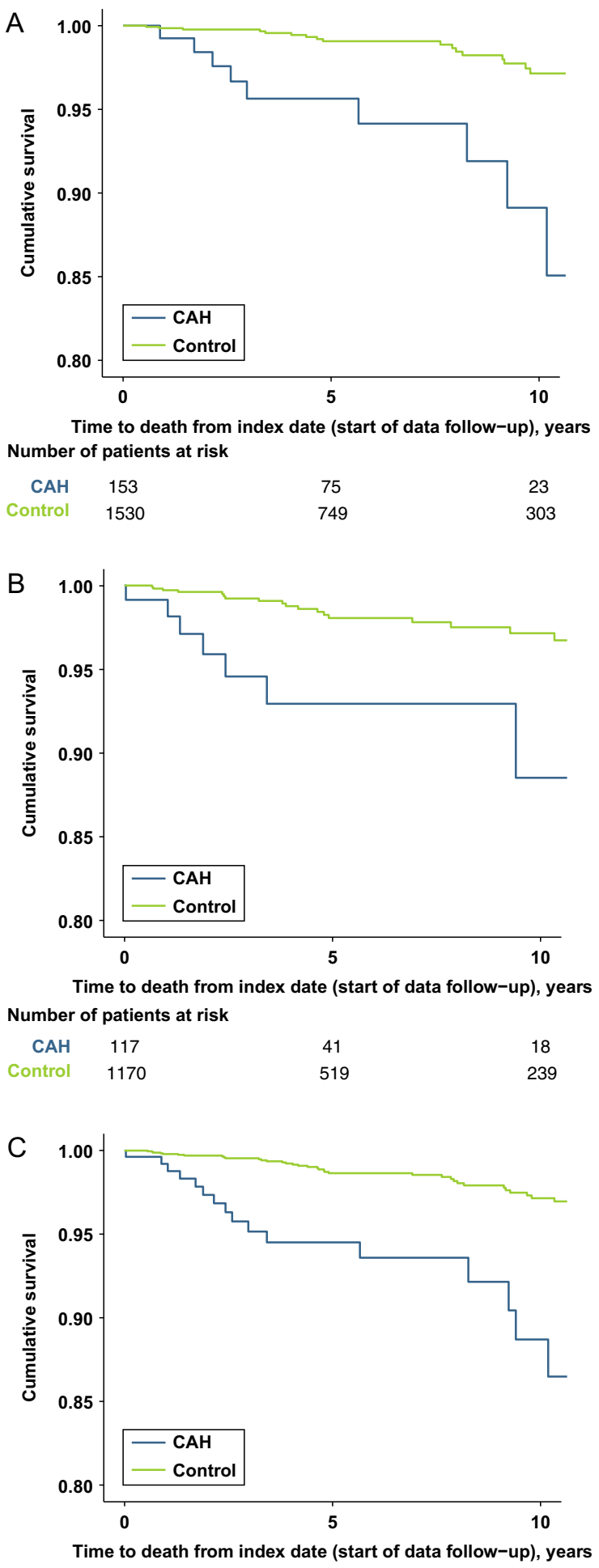
Number of patients at risk

$\begin{array}{rccc}\text { CAH } & 270 & 116 & 41 \\ \text { Control } & 2700 & 1268 & 542\end{array}$

\section{Figure 1}

Kaplan-Meier curves comparing all-cause mortality in eligible patients with $\mathrm{CAH}$ and matched control patients: (A) female patients, (B) male patients and (C) all patients. 
Table 3 Lifetime prevalence* of depression, identified by diagnostic code or antidepressant prescription, in CAH patients vs control patients.

\begin{tabular}{|c|c|c|c|c|c|c|c|c|}
\hline \multirow[b]{2}{*}{ Age at index date } & \multicolumn{3}{|c|}{ CAH patients } & \multicolumn{3}{|c|}{ Control patients } & \multirow[b]{2}{*}{ Prevalence ratio } & \multirow[b]{2}{*}{$95 \% \mathrm{Cl}$} \\
\hline & $n$ & Depression (n) & Prevalence (\%) & $n$ & Depression $(n)$ & Prevalence (\%) & & \\
\hline \multicolumn{9}{|l|}{ All ages } \\
\hline All patients & 562 & 188 & 33.5 & 5620 & 1467 & 26.1 & 1.28 & $(1.13-1.45)$ \\
\hline Female & 331 & 133 & 40.2 & 3310 & 1076 & 32.5 & 1.24 & $(1.07-1.42)$ \\
\hline Male & 231 & 55 & 23.8 & 2310 & 391 & 16.9 & 1.41 & $(1.10-1.80)$ \\
\hline \multicolumn{9}{|c|}{ Aged 17 years and younger } \\
\hline All patients & 255 & 31 & 12.2 & 2550 & 211 & 8.3 & 1.47 & $(1.03-2.09)$ \\
\hline Female & 132 & 19 & 14.4 & 1320 & 156 & 11.8 & 1.22 & $(0.78-1.89)$ \\
\hline Male & 123 & 12 & 9.8 & 1230 & 55 & 4.5 & 2.18 & $(1.20-3.96)$ \\
\hline \multicolumn{9}{|l|}{ Aged $18-40$ years } \\
\hline All patients & 226 & 97 & 42.9 & 2260 & 856 & 37.9 & 1.13 & $(0.97-1.33)$ \\
\hline Female & 152 & 78 & 51.3 & 1520 & 662 & 43.6 & 1.18 & $(1.00-1.39)$ \\
\hline Male & 74 & 19 & 25.7 & 740 & 194 & 26.2 & 0.98 & $(0.65-1.47)$ \\
\hline \multicolumn{9}{|c|}{ Aged 41 years and older } \\
\hline All patients & 81 & 60 & 74.1 & 810 & 400 & 49.4 & 1.50 & $(1.30-1.74)$ \\
\hline Female & 47 & 36 & 76.6 & 470 & 258 & 54.9 & 1.40 & (1.17-1.67) \\
\hline Male & 34 & 24 & 70.6 & 340 & 142 & 41.8 & 1.69 & $(1.32-2.17)$ \\
\hline
\end{tabular}

* Records of depression were identified from patients' ongoing data, post index date, and from past clinical histories where available.

aged $0-6$ years (a ratio of $2.4 ; P<0.001) ; £ 3766(£ 7494)$ vs $£ 1232(£ 2451)$ in those aged $7-17$ years $(3.1 ; P<0.001)$; $£ 1539$ ( $£ 872)$ vs $£ 1344$ ( $£ 1620)$ in those aged $18-40$ (1.1; $P=0.007)$; and $£ 4204$ ( $£ 4863)$ vs $£ 1651$ ( $£ 2303)$ in those aged 41 and older $(2.5 ; P<0.001)$, respectively (Table 4$)$. Mean total annual costs were highest in $\mathrm{CAH}$ patients aged 0-6 years due to frequent inpatient admissions, especially in female patients (Table 4 and Supplementary Tables 3A and $4 \mathrm{~A}$ ) and lowest in young adults aged 18-40 (Table 4 and Supplementary Tables 3C and 4C). Supplementary Tables 5 and 6 detail primary and secondary healthcare resource use and costs, respectively, for $\mathrm{CAH}$ and control patients irrespective of age. Both resource use and mean annual total primary and secondary healthcare costs were significantly higher for patients with $\mathrm{CAH}$ vs control patients. Resource use and costs remained significantly higher in the sensitivity analysis in which CAH patients were observable from, or shortly after, their first CAH record (Supplementary Tables 7 and 8) and when a larger subset of the study population was analysed, comprising $\mathrm{CAH}$ and control patients regardless of linkage eligibility (Supplementary Tables 9 and 10).

\section{Treatment adherence}

Mean (s.D.) MPR was lowest in adult patients: 78.3\% (29.8\%) in men and 78.5\% (29.3\%) in women (Table 5). In this age group, 54 (36\%) of the 150 men and 87 (35\%) of the 246 women had an MPR that had fallen below $80 \%$ (a marker of non-compliance). Adherence was highest in male patients observed from age 0 to 6: mean (s.D.) MPR $89.7 \%$ (22.2\%), with 14 patients (15\%) non-compliant and in male patients from age 7 to 17 : MPR $88.7 \%$ (23.3\%), with 15 patients (16\%) non-compliant.

\section{Discussion}

This retrospective, observational study showed that CAH patients had a higher risk of mortality and depression, increased healthcare utilisation with accompanying increased costs and poor medication adherence.

In our study, the adjusted risk of death was more than five times higher in patients with $\mathrm{CAH}$ than in a reference group of patients having no history of adrenal insufficiency, with the risk being higher in males than in females. A similar trend was observed in a Swedish setting (3), although the excess risk in patients with $\mathrm{CAH}$ (a hazard ratio of 2.3) was lower than that observed here and the difference in risk between genders was reversed. Multiple factors may have affected the results in the two countries, such as Sweden's nationwide neonatal screening programme for $\mathrm{CAH}$, introduced in 1986, and differences in sample sizes, study design and the availability of neonatal data.

Excess deaths in $\mathrm{CAH}$ have been attributed to saltwasting adrenal crises, particularly in male infants, in whom the external signs of CAH (ambiguous genitalia) are less apparent than in female infants (3). This preponderance of females identified with $\mathrm{CAH}$ in many 
Table 4 Total healthcare costs - combined NHS primary- and secondary healthcare resource costs in eligible CAH and matched control patients.

\begin{tabular}{|c|c|c|c|c|c|c|c|c|c|}
\hline & \multicolumn{4}{|c|}{ CAH patients } & \multicolumn{4}{|c|}{ Control patients } & \multirow[b]{3}{*}{$P$-Value } \\
\hline & \multirow[b]{2}{*}{ Patients } & \multicolumn{3}{|c|}{ Resource cost per year $(f)$} & \multirow[b]{2}{*}{ Patients } & \multicolumn{3}{|c|}{ Resource cost per year $(\mathrm{f})$} & \\
\hline & & Mean & S.D. & Median (IQR) & & Mean & S.D. & Median (IQR) & \\
\hline \multicolumn{10}{|c|}{ Aged 0-6 years } \\
\hline All & 51 & 7038 & 14846 & $3185(1860-5187)$ & 510 & 2879 & 13972 & $700(465-1482)$ & $<0.001$ \\
\hline Female & 24 & 8147 & 19168 & $3030(1558-4410)$ & 240 & 920 & 746 & $574(415-1250)$ & $<0.001$ \\
\hline Male & 27 & 6181 & 10821 & 3239 (2060-5249) & 270 & 4088 & 17721 & $839(496-1595)$ & $<0.001$ \\
\hline \multicolumn{10}{|c|}{ Aged $7-17$ years } \\
\hline All & 33 & 3766 & 7494 & $2183(1173-2850)$ & 330 & 1232 & 2451 & $491(290-951)$ & $<0.001$ \\
\hline Female & 18 & 4582 & 9671 & $2021(1273-2481)$ & 180 & 1447 & 3175 & 544 (317-997) & $<0.001$ \\
\hline Male & 15 & 2588 & 2112 & $2407(1173-2862)$ & 150 & 1050 & 1660 & $397(246-890)$ & $<0.001$ \\
\hline \multicolumn{10}{|c|}{ Aged $18-40$ years } \\
\hline All & 80 & 1539 & 872 & $1534(1099-1787)$ & 800 & 1344 & 1620 & $861(511-1600)$ & 0.007 \\
\hline Female & 51 & 1717 & 884 & $1622(1373-2005)$ & 510 & 1386 & 1441 & 979 (558-1734) & $<0.001$ \\
\hline Male & 29 & 957 & 540 & $1058(425-1137)$ & 290 & 1163 & 2259 & $555(284-874)$ & $<0.001$ \\
\hline \multicolumn{10}{|c|}{ Aged 41 and older } \\
\hline All & 42 & 4204 & 4863 & 2029 (1091-4482) & 420 & 1651 & 2303 & $934(496-1850)$ & $<0.001$ \\
\hline Female & 25 & 3619 & 4375 & 1595 (1091-3641) & 250 & 1491 & 2373 & $837(464-1555)$ & $<0.001$ \\
\hline Male & 17 & 5014 & 5547 & 2536 (1499-7147) & 170 & 1921 & 2172 & $1002(629-2617)$ & $<0.001$ \\
\hline
\end{tabular}

studies, as in ours, might, therefore, be due to higher numbers of male infants dying, especially in the absence of neonatal screening (19). In our study, however, there was an increased mortality in men and women in middle age, with the mean age at death of CAH patients being 54.8 years, 18 years earlier than in the matched reference group. Mean ages at death were similar in male and female patients with $\mathrm{CAH}$, at 53.3 years vs 55.8 years, respectively, and there were no deaths amongst $\mathrm{CAH}$ patients under the age of 13 years. It should be noted, however, that neonatal deaths occurring before the infant could be registered at a primary-care practice would not have been captured in our data source. The mean age of death in the control group, at 72.8 years, was younger than might be expected from the background population. However, the CAH and control cohorts were relatively young, with mean age at the start of follow-up 23.3 years and mean follow-up 5 years, therefore, one would expect the deaths that could be captured to be those occurring at a younger age.

Depression in patients with CAH was 30\% higher than in controls, increasing to nearly $40 \%$ in a sensitivity analysis of pharmaceutically treated depression. Overall and by age group, the lifetime prevalences of both depression and pharmaceutically treated depression were higher in women with CAH. It has been suggested that the experiences of women affected by virilisation and corrective surgery for ambiguous genitalia may have lasting adverse effects on their quality of life $(20,21,22)$. Previous studies of mental health in women with $\mathrm{CAH}$ have reported varying outcomes, with one UK study reporting scores for psychological outcomes within

Table 5 Adherence to oral corticosteroid therapy by age group.

\begin{tabular}{|c|c|c|c|}
\hline & $n$ & $\begin{array}{l}\text { Age at first prescription* } \\
\text { (years), mean (s.D.) }\end{array}$ & $\begin{array}{l}\text { Observation period } \\
\text { (days), mean (s.D.) }\end{array}$ \\
\hline \multicolumn{4}{|l|}{ Aged $0-6$ years } \\
\hline All patients & 181 & $1.9(2.0)$ & 1076.5 (819.9) \\
\hline Females & 87 & $2.2(2.1)$ & $964.0(817.5)$ \\
\hline Males & 94 & $1.6(1.8)$ & $1180.6(808.2)$ \\
\hline \multicolumn{4}{|l|}{ Aged 7-17 } \\
\hline All patients & 203 & $9.3(3.0)$ & 1934.7 (1377.6) \\
\hline Females & 108 & $9.5(3.2)$ & $1887.6(1408.9)$ \\
\hline Males & 95 & $9.0(2.8)$ & 1988.3 (1339.1) \\
\hline \multicolumn{4}{|c|}{ Aged 18 or older } \\
\hline All patients & 396 & $31.3(15.6)$ & $2425.9(2366.0)$ \\
\hline Females & 246 & $31.2(14.5)$ & $2515.7(2471.2)$ \\
\hline Males & 150 & $31.6(17.3)$ & $2278.6(2174.4)$ \\
\hline
\end{tabular}

\begin{tabular}{c}
\hline $\begin{array}{c}\text { Supply (days), } \\
\text { mean (s.D.) }\end{array}$ \\
\hline $975.1(803.8)$ \\
$867.2(797.9)$ \\
$1075.0(796.2)$ \\
$1729.6(1391.8)$ \\
$1669.7(1406.4)$ \\
$1797.7(1371.8)$ \\
$1847.4(2084.9)$ \\
$1920.1(2153.9)$ \\
$1728.1(1960.8)$ \\
\hline
\end{tabular}

\begin{tabular}{|c|c|}
\hline $\begin{array}{l}\text { MPR (\%), } \\
\text { mean (s.D.) }\end{array}$ & $\begin{array}{l}\text { Non-compliant** } \\
\text { patients, } n(\%)\end{array}$ \\
\hline $88.9(23.6)$ & $29(16.0)$ \\
\hline $88.1(24.9)$ & $15(17.2)$ \\
\hline $89.7(22.2)$ & $14(14.9)$ \\
\hline $87.3(25.3)$ & $37(18.2)$ \\
\hline $86.0(26.9)$ & $22(20.4)$ \\
\hline $88.7(23.3)$ & $15(15.8)$ \\
\hline $78.4(29.5)$ & 141 (35.6) \\
\hline 78.5 (29.3) & 87 (35.4) \\
\hline $78.3(29.8)$ & $54(36.0)$ \\
\hline
\end{tabular}

*First prescription while patient within age group; **non-compliance defined here as having a medical possession ratio (MPR) $<80 \%$. 
normal ranges (23) and another, again in UK patients, reporting increased scores for depression in females with classic CAH but not in those with the non-classic form (2). A matched control study in 70 Danish women with disorders of sex development, of whom 33 had CAH, found that $\mathrm{CAH}$ was associated with impaired quality of life and greater affective distress (24). In our study, the prevalence of depression varied according to age and gender: the lifetime prevalence of depression was twice as high in children and nearly $70 \%$ higher in men of 41 years and older. Arlt and colleagues (2) reported increased scores for depression in male patients with classic CAH, compared with matched controls, while Falhammar and colleagues (25) reported increased psychiatric disorders in male Swedish patients with CAH, with older patients born before the introduction of neonatal screening in 1986 being most affected. One observation from our study that may be related to these findings was that more patients with $\mathrm{CAH}$ than controls described themselves as 'ex-drinkers'. Further work on associations between alcohol and $\mathrm{CAH}$ would be interesting. It is also worth considering that the burden of $\mathrm{CAH}$ falls not only on the patient but also on their family: the parents of young children with $\mathrm{CAH}$ take on the role of primary caregiver, managing complex treatment regimens and the frequent, intercurrent childhood illnesses that could lead to adrenal crisis. Parents interviewed about their experiences have reported stress, anxiety and disruption to their sleep and working lives (26).

Annual mean healthcare costs were greater for $\mathrm{CAH}$ patients than their controls and greater for children than for adults. Mean costs in female CAH patients aged 0-6 years, at $£ 8147$ per year, were largely attributable to inpatient admissions and were nearly nine times higher than in age-matched controls. It is important to note that, because this study was based on primarycare data, the early neonatal period, the time when $\mathrm{CAH}$ characteristically presents, often as adrenal crisis, will not have been fully captured. Annual mean costs were lowest in the younger adult age group (aged 18-40 years); in female patients, these remained significantly higher than those in controls, but in male patients the position was reversed, with costs being significantly lower than those in control patients. In older adults (aged 41 years and over), annual mean costs were increased in absolute terms and were again higher than those in control patients in all comparisons. In this age group, for the first time, mean costs in male patients with $\mathrm{CAH}$ were higher than those in female patients. It is interesting to speculate whether this might be related to decreased healthcare utilisation for menstruation disorders or fertility as female patients approach menopause or increased consultations in males, perhaps associated with cardiovascular risk (27), but this needs to be investigated further. Only one other study, to our knowledge, has examined healthcare resource use and costs in patients with $\mathrm{CAH}$, but the results were similar. This matched-cohort study (28) investigated healthcare burden associated with adrenal insufficiency in a US claims database and found that healthcare costs in the CAH cohort $(n=551)$ were significantly higher than in matched, non-exposed patients, with mean expenditure (including pharmacy costs) in the year following index diagnosis of $\$ 7677$ vs $\$ 4203$, respectively.

We found children to be more compliant with their medication than adults. This was expected, as their parents would typically take responsibility for administering medication and children generally receive closer medical follow-up to monitor growth and development. However, even in the two paediatric age groups, just under $20 \%$ of patients were identified as non-compliant. Deficiencies in the transition of CAH patients from paediatric to adult care are well recognised (29) and are confirmed in this study, with a third of adult patients being non-compliant based on a medical possession ratio $<80 \%$. Noncompliance with glucocorticoid replacement therapy in CAH patients, with associated androgen excess, has been linked to reduced final adult height, impaired fertility and brain abnormalities in magnetic resonance imaging (30, $31,32)$. In addition, analysis of a US claims database has demonstrated that healthcare expenditure is reduced in patients with adrenal insufficiency who are compliant with glucocorticoid replacement therapy (28).

This study, in common with other analyses of realworld data sources, has a number of limitations. Even though the validity of medical diagnoses in CPRD (and its precursor, the General Practice Research Database) has been confirmed in several studies $(33,34)$, the use of a primary-care data set can be seen as a study limitation, given that the diagnosis and initial care for $\mathrm{CAH}$ will have been delivered in a hospital setting. Our requirement that all CAH patients should have at least one record of corticosteroid prescription in order to substantiate status led to the exclusion of approximately $45 \%$ of patients, which is suggestive that at least a proportion of the excluded patients received their medication in secondary care, which would not be recorded in the database. Due to the complexities of $\mathrm{CAH}$, the primary-care practitioner in the United Kingdom is unlikely to have been responsible for its diagnosis or its initial treatment, which will have been undertaken instead by secondary-care specialists. However, 
ongoing treatment when the disease is under control and patients have reached adulthood will, for the majority of patients, be delivered in primary care. Consequently, there exists a selection bias in our study by which younger patients and those otherwise in an early or unstable stage of the disease may be under-represented, and the overall disease burden of CAH underestimated. The requirement of at least one corticosteroid prescription may also have introduced an immortal time bias, excluding patients with CAH who died before responsibility for their therapy could be taken on by the CPRD practice. Here again, this may have led to an underestimation of mortality.

Adrenal crisis, especially in the absence of neonatal screening, is a relatively common presentation in males with classic $\mathrm{CAH}$, typically occurring at two weeks or younger (35). However, costs relating to these periods of critical care will have been under-represented in our study because the patient will not usually be registered with a CPRD practice at that age and because specific costs for neonatal and paediatric critical care are not included in the UK National Tariff, which was our source for costing inpatient admissions. An indicative cost of $£ 1000$ per bed day is, however, listed in the 2013/2014 NHS Reference Costs for paediatric critical care not requiring ventilation (17).

The prevalence for our studied patients in the data set was 1:17 135, which is slightly higher than that implied by the incidence of 1:18 000 live births reported by the British Paediatric Surveillance Unit (4). Nevertheless, it is apparent that the healthcare burden of CAH in the United Kingdom remains to be fully elucidated.

A potential weakness of our study lies in our use of non-exposed control patients instead of patients with other chronic inborn diseases in our analyses of healthcare use and costs. Over $98 \%$ of the UK population is registered with a primary-care practice (36). Therefore, a nonexposed control population derived from a source such as CPRD, particularly one in which patients are matched by age to a relatively young cohort of exposed patients, will almost certainly be largely composed of healthy individuals. Indeed, the Charlson comorbidity index generated for our adult control population (based on 19 clinical conditions, including diabetes and malignant tumour) has an interquartile range of zero, suggesting low comorbidity. A marked difference in costs between the $\mathrm{CAH}$ and control population is not unexpected therefore. However, for healthcare organizations considering the cost-effectiveness of new therapies or patient pathways, the incremental cost of care over the background population is an important measure. The value of our analyses lies in the detailed stratification of that incremental cost, which provides the economic context against with which to evaluate novel interventions for CAH. A comparison of healthcare costs in $\mathrm{CAH}$ with those in other inborn diseases falls outside the scope of this particular study but would merit future attention.

A limitation in our analysis of depression also arises from the nature of the data source: in the necessity of setting the CAH patients' index dates (and start of follow-up) as the later of their practice registration date and their first record of $\mathrm{CAH}$. There is reason to believe that the distribution of diagnoses, including that of depression, may cluster around the registration period, when patient histories are taken and initial health checks carried out. The design of our comparative analysis only required that the matching reference patient be registered at the CAH patient's index date. Consequently, the periregistration period was less well captured in the control arm of the study, which would have led to ascertainment bias if the outcome of depression were defined as incident depression subsequent to index date. We were therefore obliged to define the depression outcome as the lifetime prevalence of that condition.

In our analysis of treatment adherence, days' supply was identified from prescriptions recorded as having been issued by the primary-care practice. We have no record of whether those prescriptions were filled at a pharmacy or whether any of the supplied medicine was taken by the patient; our estimates of adherence are therefore conservative.

In conclusion and taking into account the above limitations, this is to our knowledge the first analysis of the health burden of CAH using long-term routine healthcare records. The findings that rates of depression and all-cause mortality are higher in CAH patients tally with the findings of long-term registry studies, such as those carried out in Sweden (3), and, unsurprisingly, these are reflected in patients' higher utilisation of healthcare resources. Before the introduction of glucocorticoid therapy in the 1950s, patients with CAH rarely survived into middle age. Although glucocorticoid therapy revolutionised the prognosis of the disease, much as insulin therapy transformed the care of type 1 diabetes, there has been a period of stasis in the treatment of this disease. The findings from this and other long-term studies demonstrate that further advances in therapy for patients with $\mathrm{CAH}$ are required to improve patients' quality and duration of life. 
Supplementary data

This is linked to the online version of the paper at https://doi.org/10.1530/ EJE-17-0895.

\section{Declaration of interest}

$R J M R$ and $M J W$ are directors of and $J P$ and $M W$ and $L P$ are employees of Diurnal Limited. S J J and S E H are employees of and C J C is director of Pharmatelligence, a research consultancy receiving funding from pharmaceutical companies, including Diurnal Limited.

Funding

The study was funded by Diurnal Limited.

\section{Author contribution statement}

S J J developed the study protocol, carried out the data preparation and analysis and wrote the manuscript. L P contributed to drafting the final manuscript. J $\mathrm{P}$ advised on the study question and contributed to drafting the final manuscript. M W and $\mathrm{M} J \mathrm{~W}$ advised on the study question and reviewed the final manuscript. S H E provided statistical expertise and created the corticosteroid product list. C LI M provided statistical expertise. C J C advised on the study question, analysis plan and interpretation of the study findings. R J M R advised on the study question and interpretation of the study findings.

\section{References}

1 Merke DP \& Bornstein SR. Congenital adrenal hyperplasia. Lancet 2005365 2125-2136. (https://doi.org/10.1016/S01406736(05)66736-0)

2 Arlt W, Willis DS, Wild SH, Krone N, Doherty EJ, Hahner S, Han TS, Carroll PV, Conway GS, Rees DA et al. Health status of adults with congenital adrenal hyperplasia: a cohort study of 203 patients. Journal of Clinical Endocrinology and Metabolism 201095 5110-5121. (https://doi.org/10.1210/jc.2010-0917)

3 Falhammar H, Frisén L, Norrby C, Hirschberg AL, Almqvist C, Nordenskjöld A \& Nordenström A. Increased mortality in patients with congenital adrenal hyperplasia due to 21-hydroxylase deficiency. Journal of Clinical Endocrinology and Metabolism 201499 E2715-E2721. (https://doi.org/10.1210/jc.2014-2957)

4 Khalid JM, Oerton JM, Dezateux C, Hindmarsh PC, Kelnar CJ \& Knowles RL. Incidence and clinical features of congenital adrenal hyperplasia in Great Britain. Archives of Disease in Childhood 201297 101-106. (https://doi.org/10.1136/archdischild-2011-300234)

5 Auchus RJ. Management of the adult with congenital adrenal hyperplasia. International Journal of Pediatric Endocrinology 20102010 614107. (https://doi.org/10.1155/2010/614107)

6 Porter J, Blair J \& Ross RJ. Is physiological glucocorticoid replacement important in children? Archives of Disease in Childhood 2017102 199-205. (https://doi.org/10.1136/archdischild-2015-309538)

7 Han TS, Walker BR, Arlt W \& Ross RJ. Treatment and health outcomes in adults with congenital adrenal hyperplasia. Nature Reviews Endocrinology 201410 115-124. (https://doi.org/10.1038/ nrendo.2013.239)

8 Medicines and Healthcare Products Regulatory Authority. The Clinical Practice Research Datalink. 2017. (Available at: http://www. cprd.com.) Accessed on 30 June 2017.

9 Office for National Statistics. Quality and Methodology Information (QMI): mortality statistics in England and Wales QMI. 2017. (Available at: http://www.ons.gov.uk/ peoplepopulationandcommunity/birthsdeathsandmarriages/deaths/ qmis/mortalitystatisticsinenglandandwalesqmi.) Accessed on 30 June 2017.

10 Health \& Social Care Information Centre. Hospital episode statistics. 2012. (Available at: http://www.hscic.gov.uk/hes.) Accessed on 30 June 2017.

11 Andrade SE, Kahler KH, Frech F \& Chan KA. Methods for evaluation of medication adherence and persistence using automated databases. Pharmacoepidemiology and Drug Safety 200615 565-574. (https://doi. org/10.1002/pds.1230)

12 Karve S, Cleves MA, Helm M, Hudson TJ, West DS \& Martin BC. Good and poor adherence: optimal cut-point for adherence measures using administrative claims data. Current Medical Research and Opinion 200925 2303-2310. (https://doi.org/10.1185/03007990903126833)

13 Personal Social Services Research Unit. Unit Costs of Health and Social Care 2014. 2014. (Available at: http://www.pssru.ac.uk/projectpages/unit-costs/2014/.) Accessed on 30 June 2017.

14 Health \& Social Care Information Centre. UK General Practice Workload Survey. 2007. (Available at: http://www.hscic.gov.uk/ catalogue/PUB01028/gp-work-serv-rep.pdf.) Accessed on 30 June 2017.

15 Health \& Social Care Information Centre. HRG4 2013/14 Local Payment Grouper. National Casemix Office, Winchester, UK. 2014.(Available at: http://webarchive.nationalarchives.gov. uk/20171011213304/http://content.digital.nhs.uk/article/2580/ HRG4-201314-Local-Payment-Grouper). Accessed on 8 February 2018.

16 Department of Health. Payment by results in the NHS: tariff for 2013 to 2014. 2013. (Available at: https://www.gov.uk/government/ publications/payment-by-results-pbr-operational-guidance-andtariffs.) Accessed on 30 June 2017.

17 Department of Health. NHS reference costs 2013 to 2014. 2015. (Available at: https://www.gov.uk/government/publications/nhsreference-costs-2013-to-2014). Accessed on 30 June 2017.

18 Charlson M, Pompei P, Ales K \& MacKenzie CR. A new method of classifying prognostic comorbidity in longitudinal studies: development and validation. Journal of Chronic Diseases $1987 \mathbf{4 0}$ 373-383. (https://doi.org/10.1016/0021-9681(87)90171-8)

19 Grosse SD \& Van Vliet G. How many deaths can be prevented by newborn screening for congenital adrenal hyperplasia? Hormone Research in Paediatrics 200767 284-291. (https://doi. org/10.1159/000098400)

20 Krege S, Walz KH, Hauffa BP, Körner I \& Rübben H. Long-term follow-up of female patients with congenital adrenal hyperplasia from 21-hydroxylase deficiency, with special emphasis on the results of vaginoplasty. BJU International 200086 253-258. (https://doi. org/10.1046/j.1464-410x.2000.00789.x)

21 Nordenström A, Frisén L, Falhammar H, Filipsson H, Holmdahl G, Janson PO, Thorén M, Hagenfeldt K \& Nordenskjöld A. Sexual function and surgical outcome in women with congenital adrenal hyperplasia due to CYP21A2 deficiency: clinical perspective and the patients' perception. Journal of Clinical Endocrinology and Metabolism 201095 3633-3640. (https://doi.org/10.1210/jc.2009-2639)

22 Nordenström A. Adult women with 21-hydroxylase deficient congenital adrenal hyperplasia, surgical and psychological aspects. Current Opinion in Pediatrics 201123 436-442. (https://doi. org/10.1097/MOP.0b013e32834810a4)

23 Morgan JF, Murphy H, Lacey JH \& Conway G. Long term psychological outcome for women with congenital adrenal hyperplasia: cross sectional survey. BMJ 2005330 340. (https://doi. org/10.1136/bmj.38334.427361.D3)

24 Johannsen TH, Ripa CP, Mortensen EL \& Main KM. Quality of life in 70 women with disorders of sex development. European Journal of Endocrinology 2006155 877-885. (https://doi.org/10.1530/ eje.1.02294)

25 Falhammar H, Butwicka A, Landin M, Lichtenstein P, Nordenskjöld A, Nordenström A \& Frisén L. Increased psychiatric morbidity in men with congenital adrenal hyperplasia due to 
21-hydroxylase deficiency. Journal of Clinical Endocrinology and Metabolism 201499 E554-E560. (https://doi.org/10.1210/jc.20133707)

26 Simpson A \& Hunter A. Congenital adrenal hyperplasia: parents' experiences of treating their child's condition. Endocrine Abstracts 201641 GP140. (https://doi.org/10.1530/endoabs.41.GP140)

27 Falhammar H, Frisén L, Hirschberg AL, Norrby C, Almqvist C, Nordenskjöld A \& Nordenström A. Increased cardiovascular and metabolic morbidity in patients with 21-hydroxylase deficiency: a Swedish population-based national cohort study. Journal of Clinical Endocrinology and Metabolism 2015100 3520-3528. (https://doi. org/10.1210/JC.2015-2093)

28 Gunnarsson C, Ryan MP, Marelli C, Baker ER, Stewart PM, Johannsson G \& Biller BMK. Health care burden in patients with adrenal insufficiency. Journal of the Endocrine Society 2017 1512-523. (https://doi.org/10.1210/js.2016-1064)

29 Choi J-H \& Yoo H-W. Management issues of congenital adrenal hyperplasia during the transition from pediatric to adult care. Korean Journal of Pediatrics 201760 31-37. (https://doi.org/10.3345/ kjp.2017.60.2.31)

30 Mnif MF, Kamoun M, Mnif F, Charfi N, Kallel N, Ben Naceur B, Rekik N, Mnif Z, Sfar MH, Sfar MT et al. Long-term outcome of patients with congenital adrenal hyperplasia due to 21-hydroxylase deficiency. American Journal of the Medical Sciences 2012344 363-373. (https://doi.org/10.1097/MAJ.0b013e31824369e4)
31 Nebesio TD \& Eugster EA. Growth and reproductive outcomes in congenital adrenal hyperplasia. International Journal of Pediatric Endocrinology 20102010 298937. (https://doi. org/10.1155/2010/298937)

32 Hoepffner W, Unfold A, Willgerodt H \& Keller E. Patients with classic congenital adrenal hyperplasia due to 21-hydroxylase deficiency can achieve their target height: the Leipzig experience. Hormone Research in Paediatrics 200870 42-50. (https://doi.org/10.1159/000129677)

33 Khan NF, Harrison SE \& Rose PW. Validity of diagnostic coding within the General Practice Research Database: a systematic review. British Journal of General Practice 201060 e128-e136. (https://doi. org/10.3399/bigp10X483562)

34 Herrett E, Thomas SL, Schoonen WM, Smeeth L \& Hall AJ. Validation and validity of diagnoses in the General Practice Research Database: a systematic review. British Journal of Clinical Pharmacology 201069 4-14. (https://doi.org/10.1111/j.1365-2125.2009.03537.x)

35 Joint LWPES/ESPE CAH Working Group. Consensus statement on 21-hydroxylase deficiency from the Lawson Wilkins Pediatric Endocrine Society and the European Society for Paediatric Endocrinology. Journal of Clinical Endocrinology and Metabolism 2002 87 4048-4053. (https://doi.org/10.1210/jc.2002-020611)

36 Health \& Social Care Information Centre. Attribution data set GP-registered populations scaled to ONS population estimates 2011. 2012. (Available at: http://digital.nhs.uk/catalogue/PUB05054.) Accessed on 15 January 2018.

Received 26 October 2017

Revised version received 19 January 2018

Accepted 25 January 2018 